\title{
G-Protein Coupled Receptors Dimerization: Diversity in Somatostatin Receptors Subtypes
}

\section{Ujendra Kumar*}

Faculty of Pharmaceutical Sciences, The University of British Columbia, Vancouver, BC, Canada

\begin{abstract}
Five specific receptor subtypes namely somatostatin receptor 1-5 (SSTR1-5) that are differentially expressed in central and peripheral tissue in selective manner have different role in many human pathological conditions. SSTRs possess seven-transmembrane spanning domains and are linked to G-proteins; therefore, belong to the superfamily of G-protein coupled receptors (GPCRs). There is a preponderance of evidence suggesting the importance of GPCR dimerization in receptor-biogenesis, regulation and pharmacology. SSTR subtypes dimerization, with specific interest on the formation of heterodimers within the family or other related receptors, generates novel receptors with unique pharmacological, biochemical and enhanced signaling properties distinct from those of the native receptor existing as monomers or dimers. An understanding of the molecular mechanisms involve in SSTR dimerization could offer a rationale in future drug design. Importantly, gaining insights on the structure, function and signaling pathways of SSTR subtypes would represent a major advance in improving the treatment of various diseases such as neurodegenerative diseases and the tumors of various origins. In addition to discuss the significance of SSTR subtypes homo-and heterodimerization in particular, this review first describes the concept of GPCRs dimerization and the role of key membrane associated signaling proteins.
\end{abstract}

\begin{abstract}
Abbreviations: $\beta 1$ and $\beta 2$ AR: Adrenergic Receptors; cAMP: Cyclic Adenosine Mono Phosphate; CGRP: Calcitonin Gene Related Peptide; CHO-K1: Chinese Hamster Ovary cell line; DR: Dopamine Receptor; ERKs: Extracellular signal-Regulated Kinases; EGF: Epidermal Growth Factor; EGFR: Epidermal Growth Factor Receptor; FCS: Fluorescence Correlation Spectroscopy; FSK: Forskolin; GABAR: Gamma-Aminobutyric Acid Receptors GPCRs: G-Protein Coupled Receptors; Grb2: Growth factor receptor-bound protein 2; GRK: GPCR Kinases; GH: Growth Hormone; GTP: Guanosine-5'-Triphosphate; SSTR: Somatostatin Receptor; HA: Hemagglutinin; HEK-293: Human Embryonic Kidney-293; HHRs: Heptahelical Receptors; MAPK: Mitogen-Activated Protein Kinase; Ors: Opioid Receptors; Pb-FRET: Photobleaching- Fluorescence Resonance Energy Transfer; PARP1: Poly (ADP-ribose) Polymerase; PCNA: Proliferating Cell Nuclear Antigen; PTP: Protein Tyrosine Phosphatase; RAMPs: Receptor Activity-Modifying Proteins; RTK: Receptor Tyrosine Kinases; SST14: Somatostatin-14; SSTRs: Somatostatin Receptors; TM: Trans Membrane; TRs: Taste Receptors; TUNEL: Terminal deoxynucleotidyl transferase dUTP Nick End Labeling.
\end{abstract}

\section{Introduction}

G-protein coupled receptors (GPCRs) constitute the largest members of cell surface transmembrane signaling proteins that exert critical role and form the basis of the most important signaling pathways. The human genome comprises approximately 1000 members of GPCRs family that response to extracellular stimuli such as light, ions, small molecules, peptides, hormones and neurotransmitters. On the basis of sequence similarity GPCRs are divided into three distinct families A, $\mathrm{B}$ and C. Family A is the largest and highly heterogeneous family of GPCRs and includes rhodopsin, the adrenergic receptors, the olfactory and members of the Somatostatin receptor (SSTR) family. Family B is a small family of GPCRs, consists the gastrointestinal peptide hormone receptor family, corticotrophin- releasing hormone, calcitonin and parathyroid hormone receptors. Family $\mathrm{C}$ also known as the glutamate family includes metabotropic glutamate receptor family, the GABAB receptor and the calcium-sensing receptor (CaSR) and taste receptors (TRs) [1]. One of the most prominent characteristics of GPCRs is the heterodimerization within the family or distantly related receptors.
Several previous studies culminated in the unveiling of a family of SSTRs comprised of five isoforms of closely related size, termed SSTR1 to SSTR5. The five SSTR subtypes display the seven a helical transmembrane segments typical of heptahelical receptors (HHRs) and belong to family of GPCRs [2]. SSTR subtypes share a high degree of amino acid sequence identity, ranging from 37 to $59 \%$ [2-4]. All SSTR subtypes share the structural motif in the seventh transmembrane domain, which serves as a signature sequence for the receptor family [2]. SSTR subtypes are coupled to multiple second messenger systems through their specific interaction with pertussis toxin-sensitive heterotrimeric G proteins [2]. All SSTRs display acute G-protein uncoupling in response to treatment with SST and undergo rapid internalization, except SSTR1 [5-13]. SSTR1 is the only receptor subtype that is upregulated at the cell surface in response to agonist activation. In contrast, SSTR3 is the only receptor subtype which internalizes the most and does not recycle back to the membrane; and rather targeted for degradation [2]. The distinct pattern of expression and multifunctional properties of SSTR subtypes elucidate the complexities in somatostatinergic system. In human, SSTR subtypes play crucial role in central and peripheral tissue and produce a different array of endocrine, exocrine, neuronal and immune cell to inhibit secretion, modulate neurotransmission and regulate cell proliferation. Increasing biochemical and functional evidence suggest that GPCRs display homo and heterodimerization or even the formation of higher degree of oligomers which are associated with distinct pharmacology

*Corresponding author: Ujendra Kumar, Professor, Faculty of Pharmaceutical Sciences, The University of British Columbia, Canada, Tel: (604) 827-3660; Fax: (604) 822-3035; E-mail: ujkumar@mail.ubc.ca

Received August 19, 2013; Accepted November 01, 2013; Published November 07, 2013

Citation: Kumar U (2013) G-Protein Coupled Receptors Dimerization: Diversity in Somatostatin Receptors Subtypes. J Pharmacogenom Pharmacoproteomics 4: 120. doi:10.4172/2153-0645.1000120

Copyright: (c) 2013 Kumar U. This is an open-access article distributed under the terms of the Creative Commons Attribution License, which permits unrestricted use, distribution, and reproduction in any medium, provided the original author and source are credited. 
and agonist induced receptor trafficking. SSTR subtypes pharmacology, trafficking and receptors mediated signaling have been reviewed extensively elsewhere $[1,2]$. This review will focus on homo-and or heterodimerization of SSTR subtypes and discussed the role of key effectors molecules which might regulate GCPRs signaling and trafficking.

\section{G-protein coupled receptors and dimerization}

Protein-protein interaction of cell surface proteins is considered one of the most dynamic responses of cells. The concept that GPCRs exist and function in monomeric entities at the cell surface has recently been challenged. Several recent biochemical and functional studies suggest that most if not all GPCRs function as homo-and heterodimers or even higher order of oligomers. Upon agonist activation, GPCRs initiate a cascade of responses by regulating a class of three-subunit proteins termed G-proteins, named for their binding to guanosine triphosphate (GTP). GPCRs share common structure as seven transmembrane-sparing helices with extracellular $\mathrm{N}$ and intracellular $\mathrm{C}$ terminus (C-tail). In addition to exhibit desensitization, sequestration, down-regulation or even up-regulation, importantly dimerization/ oligomerization is one of the unique modes of GPCR regulation and has been reviewed in great depth [14-17]. It is now well established that many cell surface receptors form oligomeric structures as a prerequisite for signal transduction. For instance, in pituitary cells, the importance of luteinizing hormone-releasing hormone receptor dimerization has been shown to be essential in the release of luteinizing hormone [18]. The earliest direct physical evidence for GPCR dimers formation came from investigation on immunoaffinity chromatography and western blot analysis of $\beta_{2}$-adrenergic receptors ( $\beta_{2}$ ARs) from lung origin [19] and covalent cross-linking of angiotensin II to its binding sites in rat adrenal membranes [20]. Additional evidence for the dimerization of GPCRs came from radiation inactivation and photoaffinity labeling experiments, where a number of receptors were demonstrated to be larger than predicted based on simple monomeric structures [21]. The process of receptor dimerization has been shown in the endoplasmic reticulum, the site of the receptor synthesis indicating role of receptor dimerization at the early stage of receptor synthesis [22].

Development of recombinant DNA expression systems has served as an instrumental tool to study the functional significance of GPCR dimers. Various GPCR mutant or chimeric constructs could be reconstituted when co-transfected in cells. For instance, when two functionally inactive GPCR chimeras, one possessing the first five transmembrane domains (TMs) of the a2-adrenergic receptor and the last two TMs of the muscarinic $\mathrm{m} 3$ receptor and vice versa, allowed for restoration of both receptors functionality [23]. Similar results have also been described for the angiotensin II receptor [24]. Several other member of GPCRs family such as the luteinizing hormone and vasopressin V2 receptors also behave in same manner [25-28]. The formation of dimeric or even oligomeric receptor-complexes is additionally supported by complementation assays [21]. One of the early studies on $\beta$-adrenergic receptor dimerization provides the first convincing evidence of the functional significance of GPCR dimerization [29]. In this study, Hebert et al. described the effects of peptide mimicking TM VI of the $\beta_{2} \mathrm{AR}$ [29]. Authors finding were quite intriguing, as the treatment of $\beta_{2} \mathrm{AR}$ expressing cells with the peptide, blocked dimerization and agonist induced signaling. Furthermore, the effect was specific to peptides corresponding to TM VI of the receptor, as other TM peptides had no effect. Ligands also play critical role in the equilibrium of the complex treatment with the agonist isoproterenol stabilized the dimers and prevented the TM peptide from interfering whereas inverse agonists were found to favor the stability of monomers. A functional role for the dimerization of $\delta$-opioid receptor $(\delta \mathrm{OR})$ has also been reported, however, in this case, agonist treatment resulted in the dissociation of pre-existing dimers, a property that when perturbed, disrupt receptor internalization [30].

\section{Exploration of receptor dimerization}

The cloning and characterization of the $\gamma$-aminobutyric acid receptor $B_{1}\left(G A B A_{B} R 1\right)$ trigger the importance of GPCR dimerization [31]. However, although the receptor was capable of binding GABA agonists when expressed in cells, it was largely non-functional and incapable of efficiently coupling to potassium channels. Interestingly, receptor is largely retained intracellularly due to inefficient transport to cell surface. Later, a second $\mathrm{GABA}_{\mathrm{B}}$ subtype was cloned and termed $\mathrm{GABA}_{B} \mathrm{R} 2$. Unlike $\mathrm{GABA}_{\mathrm{B}} \mathrm{R} 1$, this receptor-subtype could traffic to the cell surface but did not bind GABA agonists. It was only following the co-expression of both receptor-subtypes did the formation of a fully functional $\mathrm{GABA}_{\mathrm{B}}$ receptor that displayed efficient trafficking to the cell surface [32-37]. Assembly and cell surface targeting of the $\mathrm{GABA}_{\mathrm{B}}$ receptor occurs primarily at its carboxyl-terminus [34,37,38], although it has been demonstrated that heterodimerization can occur through other regions such as their transmembrane domains $[38,39]$. The carboxyl-terminus of $\mathrm{GABA}_{\mathrm{B}} \mathrm{R} 1$ possesses a motif that retains it in the endoplasmic reticulum, however, this motif is masked by interaction with the C-terminus of $\mathrm{GABA}_{\mathrm{B}} \mathrm{R} 2[34,37,38]$. These studies were the first to provide strong evidence on the importance of GPCR dimerization in receptor transport and function. Further in support, studies on taste receptors revealed that heterodimerization between receptor-subtypes plays an important role in receptor function. As described, cells expressing T1R1, T1R2 or T1R3, were unresponsive to sweet stimuli [40-46]. Most importantly, cells cotransfected with T1R2 and T1R3 caused receptor-activation in presence of sweet tastants [45], suggesting the formation of functional heteromeric complex. In addition to the GABA $\mathrm{B}_{\mathrm{B}}$ and taste receptors, other members of the class $C$ family of GPCRs have also been reported to exist as dimers. For instance, calcium-sensing receptor and the metabotropic glutamate receptor subtype-5 exist as constitutive disulfide-linked dimers [47-50]. Furthermore, crystal-structure analysis of the large $\mathrm{N}$-terminal portion of the metabotropic glutamate receptor subtype-1, revealed it to exist as a dimers hinged by disulfide bonding [51]. A large body of accumulated studies indicates that GPCRs dimerization is not restricted amongst the members of this family but also expanded to other receptor categories. These expansions of protein-protein interaction have been possible only by improved methodological approaches. Interestingly, recent studies suggest that GPCR can also form heterodimers with ligand gated channels such as $\mathrm{N}$-methyl-D-aspartate receptors (NMDARs) and GABA-A receptors as well as receptor tyrosine kinase family [5256].

\section{Methodological advances in understanding of receptor dimerization}

Although, several studies as discussed above contribute significantly to our understanding on the dimerization of GPCRs were largely accomplished using classical biochemical techniques. Since disulfide cross linking is irreversible and occurs in time dependent manner limited these observations on stable and transient complex formation. Furthermore, lack of large extracellular domain in class A subfamily of GPCRs is not supportive to disulfide linkage. In 2000, this caveat in cross linking overcomes by using resonance energy transfer (RET) [57-59]. In particular, the application of RET techniques has served 
as an instrumental tool to study GPCRs. One of the most common RET techniques used in the study of GPCR dimerization called bioluminescence energy transfer (BRET) was first adopted to study $\beta_{2}$-adreneric receptor dimerization in living cells [57]. Although, the technique has its advantages as well as limitation, there is one intrinsic disadvantage when studying GPCRs; BRET cannot discriminate between dimers present at the cell surface or those present during synthesis in the endoplasmic reticulum. Another technique that also overcomes the problems of direct fluorescence energy transfer (FRET) measurements is photobleaching FRET (pbFRET), which exploits the photobleaching process of fluorophores. The application of pbFRET was originally developed by Gadella TW Jr and Jovin TM, Kubitscheck $\mathrm{U}$ et al. and Young RM, et al. in the early 90's [60-62], and introduced to study the dimerization of SSTRs $[59,63]$. Donor photobleaching FRET is the process of photobleaching the donor fluorophore under the intense illumination of its excitation wavelength, while measuring the changes in the intensity of its fluorescence in the absence or presence of the acceptor fluorophore. If the acceptor is in close enough proximity to the donor, (10-100 Á), FRET occurs and competes with the photobleaching process, decreasing the rate of photobleaching. One advantage in using this method is that the time constants are measured in the second to minute range unlike regular FRET which occurs in nanosecond time scale, thereby omitting the need for complex digital imaging instrumentation. Given the small distance that is needed for FRET to take place, it can be assumed that the receptors are in association. The pbFRET technique is not restricted to the use of conjugated antibodies, as fluorescently labeled ligands $[64,65]$ and receptors fused with the different variants of green fluorescence proteins have also been used [66]. These two techniques have been used extensively to determine protein-protein interaction and contributed significantly to structure, function and regulation of GPCRs. Accordingly, the data discussed here regarding SSTR homo-and heterodimerization are generated by using pb-FRET analysis and classical biochemical methodologies. The use of these advance techniques provided new insight in our understanding of receptor orientation, stoichiometry and close proximity of interacting proteins as homo and heterodimers. Furthermore, there are key signaling membrane associated proteins also play crucial role in GPCR mediated signaling pathways with or without receptor specific agonist.

\section{Molecular determinant of GPCRs dimerization}

The prominent characteristic properties of GPCR including binding, trafficking and signaling is not only dependent on GPCR but is also directed by some cell membrane associated proteins which interact with these receptors [67]. To execute distinct, selective and specific degree of responses including those of signaling message, cells have an ability to reorganize several key signaling proteins in a precise manner and orientation in a prearranged membrane atmosphere along with GPCRs and adaptor proteins [68]. Amongst them are the GPCRs which respond to external and internal stimuli and determine the cell message. In addition to classical biochemical and pharmacological applications, significant methodological progress and advances have been made to understand the structure, function and regulation of GPCRs in last ten years. However, elucidating the functional consequences of such interactions and understanding of the molecular mechanism involved will serve as an excellent experimental tool in search of novel therapeutic drugs. Since these proteins have a tendency to interact with different GPCRs, that makes it difficult to identify a drug which can induce disruption of this intricate protein-protein interaction [69]. GPCRs govern significant importance as therapeutic drugs target, however due to complex protein purification procedures leading to insufficient protein amount, the knowledge gained so far on structural organization and characterization of these receptor proteins by using NMR and crystallography posed some limitations [70].

To overcome these technical limitations and to define the molecular details of these critical integrated cell surface protein-protein complex formation and ligand-protein interaction, the use of mass spectrometry (MS) analysis has been explored. While MS is the best tool to study post translational changes but have not been used frequently to study GPCRs because of the poor expression and highly hydrophobic nature of TM domain which contain a site for ligand binding. Therefore, improved ways to yield high production of membrane proteins and proteomics analysis are in immediate need [70]. Identification of specific residue in receptor protein responsible for different function including glycosylation and binding sites for small molecules will enable us to develop therapeutically beneficial drug candidates.

While many members of GPCRs family tend to couple selectively to a specific G protein, single GPCR can also couple to multiple heterotrimeric $G$ proteins including purinoceptor (P2Y11), $\beta_{2} \mathrm{AR}$, $\beta_{3} \mathrm{AR}, 5 \mathrm{HT} 2 \mathrm{C}$ and dopamine receptor subtypes [71]. Such a dynamic and functional interaction between GPCRs and G proteins is often monitored by agonist binding. SSTR subtypes which are generally coupled to Gi have also been reported to couple $G_{a 14}$ which is a member of the $\mathrm{Gq}$ family in cells and receptor specific manner [72].

In addition to heteromeric G-proteins which couple to GPCR, receptor signaling and trafficking are also closely monitored by intracellular GPCR-interacting proteins such as G-protein couple receptor kinases (GRK) and $\beta$-arrestin associated pathways that have been studied extensively [73-78]. In particular, SSTR subtypes heterodimerization alters the association kinetics of $\beta$-arrestin to SSTR2 and enhances the receptor expression back to cell surface with increased inhibition of adenylate cyclase, activation of MAPKs and up-regulation of the cyclin-dependent kinase inhibitor p27 $7^{\mathrm{Kip} 1}$ are all features observed after receptor heterodimerization [79].

Recently changes in GPCRs pharmacology specifically for the members of B family commonly known as secretin family has been shown to be modulated by type 1 protein known as receptor activitymodifying proteins (RAMPs). RAMP1 exhibits 30\% identity with RAMP 2 and RAMP 3 and are differentially expressed at the molecular levels and exert distinct role on receptor pharmacology [80-82]. The role of RAMPs is not only limited to class B family but has also been shown to be associated with calcium sensing receptor trafficking to the cell membrane from endoplasmic reticulum as well as receptor glycosylation $[83,84]$. These observations altogether indicate that the role of RAMPS is not limited to family B but may also influence the functionality of other GPCRs. In addition, certain other molecules also play crucial role in GPCRs mediated signaling and trafficking directly or indirectly includes Regulators of G-protein signalling (RGS) which are linked to GPCR signaling termination due to GTP activated hydrolysis. GPCR-associated sorting proteins (GASPs), Homer proteins and PDZ proteins have also been associated with modulation of GPCRs function [82].

The integrated membrane-associated entities including receptors, $G$ proteins, effector molecules and enzymes as well as small essential proteins are intimately associated with GPCR signaling directly or indirectly. Furthermore, apart from these crucial proteins as discussed above, GPCRs compartmentation and arrangement at cell surface also play pivotal role on GPCRs pharmacology, trafficking and signaling pathways. Consistent with the existing notion that rapid signaling is a unique feature of GPCRs, low levels of receptor and uneven 
distribution of these key signaling molecules in cells fail to translate the rapid signaling responses. To overcome this biological hurdle, cells have an ability to accommodate these signaling molecules in specific microdomain with in the membrane to exert rapid response. Such well studied and established microdomains in the plasma membrane are considered to be lipid rafts composed of sphingolipid and cholesterol.

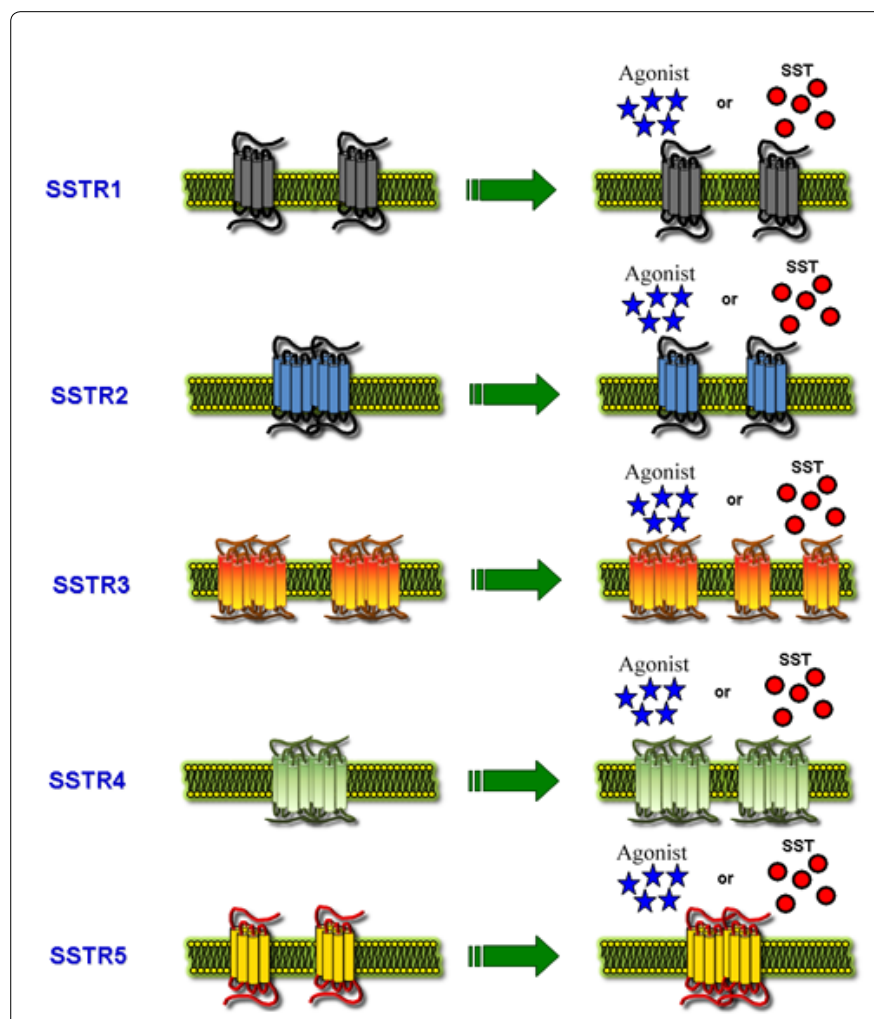

Figure 1: Schematic illustration showing receptor specific dimerization of somatostatin receptor subtypes in absence or presence of agonist. SSTR1 exist as monomer with or without agonist. SSTR2 exist as a constitutive dimer and dissociates upon agonist treatment. SSTR3 is a preformed dimer and following treatment with agonist dissociates partially to monomer. SSTR4 exist as dimer and dimerization is further stabilized in presence of agonist treatment. Conversely, SSTR5 in basal condition exist as monomer however, upon agonist treatment exhibited dimerization.

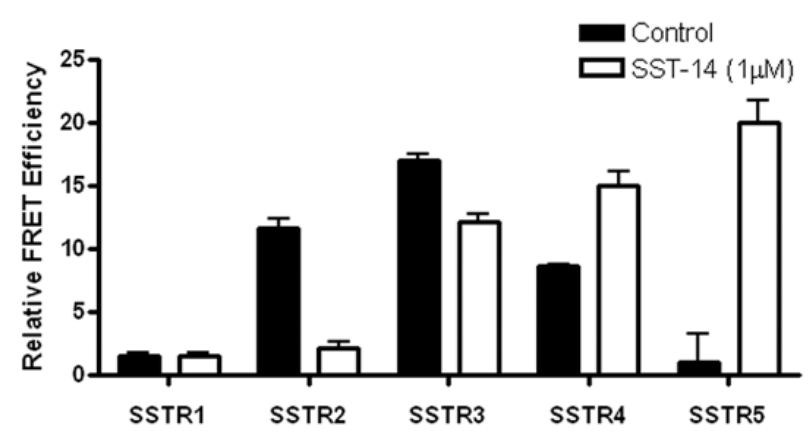

Figure 2: Histograms depicting relative FRET efficiency in HEK-293 cells stably transfected with SSTR subtype 1-5. FRET efficiency was determined at cell surface by using microscopic Pb-FRET analysis in control and upon SST treatment. Changes in relative FRET efficiency are indicative of receptor dimerization. Note the distinct but significant changes in SSTR2 and SSTR5 upon agonist treatment.
Thus, enrichment of GPCR signaling components in lipid rafts or caveolae may be a universal mechanism for increasing the effective concentration of these proteins by restricting their movement, diffusion constant and velocity thereby favoring interaction of these proteins in the signal transduction pathway. The presence of receptor proteins in lipid raft not only influences signaling but also involve in regulation of receptor trafficking.

Previous studies attest the role of preferential compartmentation of GPCR signaling proteins in caveolae or lipid rafts as a major determinant of receptor- effector coupling. For instance, in cardiac myocytes, $\beta_{1} \mathrm{AR}$ and $\beta_{2} \mathrm{AR}$ are confined in caveolae or lipid rafts in association with membrane Gs and exert crucial role in activation of AC in isofrom specific manner [85-90]. In contrast, some GPCR as well as $G$ protein are devoid of their presence in lipid raft fractions and do not couple to AC such as EP2 receptors in cardiac myocytes.

\section{Somatostatin receptors: an example of diversity in dimerization}

Somatostatin receptors homodimerization: The distributional pattern, presence of multiple receptors on a single cell and pharmacological properties of SSTR subtypes or other members of GPCRs family provide the first evidence that these receptors might function in a concert to enhance the receptor function or even might blunt the cell responses upon agonist binding. One of the best established examples is the inhibition of forskolin stimulated cAMP. In the case of SSTRs, previous studies have shown a great diversity in response to agonist induced activation [91]. All five SSTR subtypes have been described for dimerization and there are compelling evidences for the agonist dependent dimerization of SSTRs in receptor specific manner using a combination of morphological, pharmacological, biochemical and biophysical techniques [59,63]. As illustrated in Figures 1 and 2, SSTR subtypes display distinct pattern of dimerization in basal condition and following agonist treatment. SSTR1 appears to be unique among SSTRs that exist as a monomer in monotransfected cells with or without agonist activation. This specific nature of SSTR1, whether expressed in Chinese hamster ovary (CHO-K1) or Human Embryonic Kidney cells (HEK-293) may be mechanistically linked to its lack of internalization even upon prolong agonist treatment $[6,8,65,92]$. SSTR1 monomers exhibit efficient receptor coupling which suggests a functionally active receptor even as monomer. Thus the criterion for receptor to be active only when they form dimers does not remain the absolute requirement for its functionality. However, switching SSTR1 C-tail with the C-tail of SSTR5 enables SSTR1 to exhibit dimerization, indicating the sequence of amino acid arrangement in C-tail could play determinant role. Whether or not SSTR1 function in a similar manner in neuronal or other cells expressing receptor endogenously need to be determined.

The human SSTR2 in basal condition exists as a constitutive homodimer at the cell surface and dissociates into monomers upon agonist treatment $[64,93]$. The existence of constitutive GPCR dimers and ligand-induced dissociation of other GPCR heterodimers has been demonstrated [30,94-99]. Cvejic and Devi reported that $\delta$-opioid receptor dimers dissociation was necessary for receptor-internalization [30]. In contrast, regulated dimerization of the platelet activating factor receptor and the thyrotropin-releasing hormone receptor were shown to increase internalization [100,101]. SSTR2 homodimers like $\delta \mathrm{OR}$ dimers regulates receptor internalization tempted further crosslinking studies which demonstrated that preventing dissociation of SSTR2 homodimers hampers the rate of receptor internalization 
[64]. Interestingly, porcine SSTR2 dimers display dissociation prior to internalization [93]. Taken in consideration these studies suggest that dissociation of SSTR2 is a common characteristic in all species and is a prerequisite of receptor internalization.

SSTR3 from rodent origin exists as a constitutive homodimer with or without ligand binding [99]. In comparison to rat SSTR3, human SSTR3 also exists as preformed dimer which decreases upon treatment with receptor specific agonist [102]. In addition to the differences in receptor origin, the methodology used in these two studies may account for discrepancy. Pfeiffer et al. used co-immunoprecipitation where as War et al. applied microscopic pbFRET analysis [99,103]. Recent study dealing with somatostatin receptor-3 (SSTR-3) described a distinct pattern of internalization upon agonist activation and also its association in induction of apoptosis [102]. The presence of SSTR3

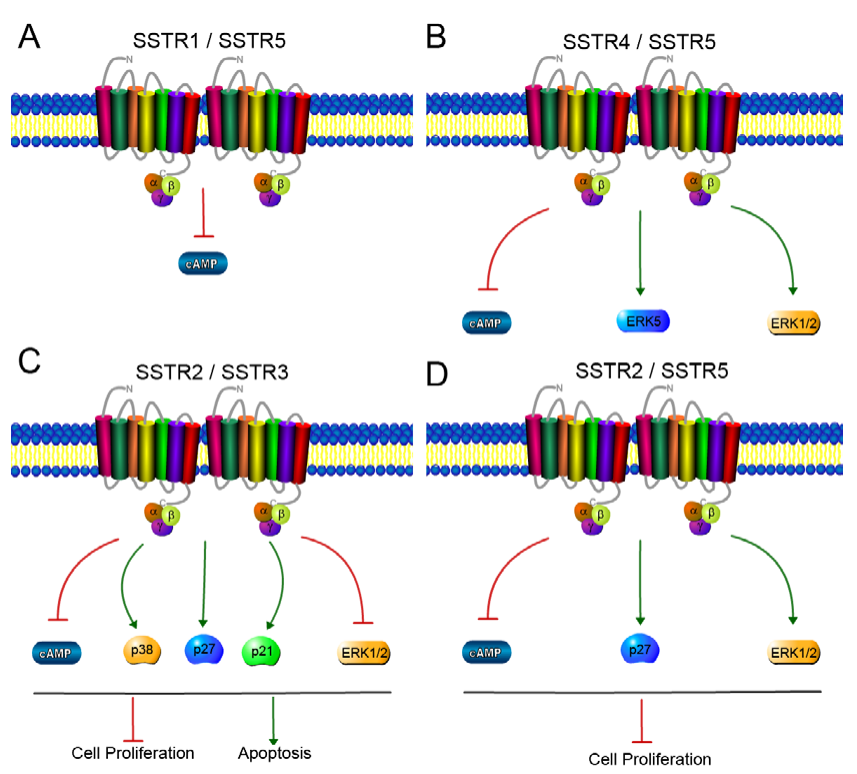

Figure 3: Schematic illustration showing heterodimerization of somatostatin receptor subtypes and consequent modulation of downstream signaling pathways. Signaling pathways indicated represent only those which have been identified so far upon receptor heterodimerization. Pathways indicated in red and green identify inhibitory and stimulatory role of SSTR subtypes respectively. This illustration was constructed using the online pathway builder from Protein Lounge (http://www.proteinlounge.com).

\begin{tabular}{|c|c|c|}
\hline Receptors & Homodimers /Heterodimers & References \\
\hline SSTR1 & $\begin{array}{l}\text { SSTR1* } \\
\text { SSTR4* } \\
\text { SSTR5 }\end{array}$ & {$[59,65,92,106]$} \\
\hline SSTR2 & $\begin{array}{l}\text { SSTR2 } \\
\text { SSTR3 }^{* *} \\
\text { SSTR5 }\end{array}$ & {$[64,79,99]$} \\
\hline SSTR3 & $\begin{array}{l}\text { SSTR2** }^{*} \\
\text { SSTR3 }\end{array}$ & {$[99,102]$} \\
\hline SSTR4 & $\begin{array}{l}\text { SSTR1* } \\
\text { SSTR4 } \\
\text { SSTR5 }\end{array}$ & {$[106]$} \\
\hline SSTR5 & $\begin{array}{l}\text { SSTR1 } \\
\text { SSTR2 } \\
\text { SSTR4 } \\
\text { SSTR5 }\end{array}$ & {$[59,65,79,106]$} \\
\hline
\end{tabular}

${ }^{*}$ Homo or heterodimerization not detected

${ }^{* *}$ Receptor of rat origin

Table 1: Somatostatin receptors homo-and/or Heterodimerization.
C-tail plays a crucial role on receptor cell surface expression, coupling to adenylyl cyclase, downstream signaling pathways and apoptosis in HEK-293 cells expressing wt-SSTR3 or C-tail deleted mutants. Furthermore, SSTR3 mediated inhibition of forskolin-stimulated cAMP was diminished with gradual extension of deletions in receptor C-tail. Importantly the C-tail of several other members of GPCR family has been shown to be associated with receptor dimerization. Accordingly, the results from War et al. studies describing the role of SSTR3 in C-tail deleted mutants may be due the loss of receptor dimerization [102].

Amongst all the SSTR subtypes, SSTR4 is the only receptor which has been studied the least. However, the mechanistic and physiological importance of the SSTR4 is derived from the receptor knockout mice $[104,105]$. These studies cumulatively suggest that lack of SSTR4 exhibit sustained pain and loss of analgesic effect $[104,105]$. Using biochemical and biophysical techniques SSTR4 dimerization, trafficking, coupling to adenylyl cyclase and signaling in HEK-293 cells has recently been described [106]. SSTR4 exogenously expressed in HEK-293 cells exhibits homodimerization, inhibits forskolin-stimulated cAMP, display agonist dependent changes in pERK1/2 and pERK5 expression. Upon C-tail deletion, receptor loses membrane expression, ability to dimerize and inhibition of cAMP however, displays several-fold increase in expression of $\mathrm{pERK} 1 / 2$.

Unlike other SSTR subtypes, SSTR5 exists as monomer in basal condition and display dimerization in presence of agonist [59]. This is just opposite to SSTR2, despite the fact both receptors internalize upon agonist treatment but respond to agonist differently to exhibit dimerization. Interestingly, upon agonist binding SSTR2 display dissociation of preformed dimers, conversely SSTR5 exhibit dimerization in concentration dependent manner. As discussed earlier, the expression levels of receptor play critical role on homodimerization. Previous studies described that over expression of SSTR5 resulted in aggregation at cell surface whereas low expression comparable to physiological expression does not exhibit dimerization. Whether all five SSTR subtype internalizes as monomer or dimers or this process is receptor selective is not known, however these observations speculate that upon ligand binding receptor configuration at cell surface might play determinant role and need to be determined.

\section{Heterodimerization of somatostatin receptor within the family}

In addition to displaying receptor specific dimerization, SSTR subtypes have shown great diversity to perform heterodimerization and regulation of signaling pathways (Figure $3 \mathrm{~A}-\mathrm{D}$ and Table 1 ). There are ten different combinations for SSTR subtypes to constitute heteromeric complex. Pfeiffer et al. using rodent origin of SSTR2 and SSTR3, demonstrated that these receptor subtypes are constitutively homoand heterodimerize when coexpressed in HEK 293 cells [99]. SSTR3selective agonist L-796,778 showed a marked decrease in binding affinity in SSTR2/SSTR3 co-expressing cells, suggesting negative cooperativity between these receptor subtypes. The SSTR2/SSTR3 heterodimers displayed features of SSTR2 expressing cells such as, GTP binding, inhibition of adenylyl cyclase and ERK1/2 phosphorylation, but displayed relatively greater resistance to agonist-induced desensitization [99]. While the physiological relevance for these process is yet to be determined, it is important to note that these receptors are found to colocalize in tissues of clinical interest, such as the pancreas, the anterior lobe of the pituitary and in medulloblastoma temporal cells $[99,107]$. In early developmental stages of rat brain, the cerebellum exhibit high levels of SSTR2 and SSTR3 mRNA expression however 
display absence of SSTR3 binding sites, which is well correlated with the SSTR2-mediated inactivation of SSTR3 upon heterodimerization [108]. Although, these are interesting observations, however, further studies are anticipated in this direction to support the concept that receptor heterodimerization may also blunt the functional properties of native receptors.

SSTR2 and SSTR5 were shown to directly interact, a mechanism regulated by agonist binding [79,109]. SSTR2 and SSTR5 heterodimerization was induced by selective SSTR2 agonist treatment and not with the endogenous pan-agonist SST-14 [79], that has been demonstrated to enhance hSSTR1/hSSTR5 heterodimers formation $[59,65,92]$. Several heteromeric interactions have been found to be equally fostered following activation of just one of the receptor protomers $[59,110,111]$, despite that it has been shown that stabilization of heterodimers between members of other family A GPCR subfamilies requires concurrent stimulation [96,112-117]. The SSTR2/SSTR5 heterodimers resulted in an approximate 10-fold increase in efficiency for G-protein coupling and activation of MAPK which consequently led to an extended growth inhibitory response accompanied with an increased expression levels of the cyclin-dependent kinase inhibitor p27 ${ }^{\text {Kip1 }}[79]$.

Somvanshi et al. by performing C-tails switching between SSTR4/ SSTR1 and SSTR4/SSTR5 described that, chimeric SSTR4 with the C-tail of SSTR5 functions like wt-SSTR4, in contrast, with the C-tail of SSTR1 chimeric receptor functions like C-tail deleted hSSTR4 [106]. hSSTR4 dimerization and signaling are associated with increased cyclin-dependent-kinase $\mathrm{p} 27^{\mathrm{Kip} 1}$ expression and inhibition of the cell proliferation. Authors also reported that SSTR4 forms heterodimers with SSTR5 but not with hSSTR1 with significant changes in receptor function. In addition, SSTR4 also elicits variable coupling in HEK293 cells in comparison to CHO-K1 cells. Most importantly, hSSTR4 does not couple to G-proteins or to adenylyl cyclase when transiently transfected in CHO-K1 cells due to the absence of the $\mathrm{G}_{\mathrm{ial}}$ [118]. This study clearly defines a novel mechanism for the role of hSSTR4 in cell proliferation and modulation of signaling pathways in cell specific manner [106].

Rocheville et al. described for the first time that SSTR1 and SSTR5 subtype exist in heteromeric complex [59]. As discussed above, SSTR1 is the only receptor subtype which does not internalize upon agonist treatment and is rather upregulated at cell surface. Conversely SSTR5 exhibited time dependant internalization. However, SSTR1 exhibit internalization in cells cotransfected with SSTR1/SSTR5 a phenomenon attributed to receptor heterodimerization $[59,63]$. In parallel to these observations homo-and heterodimerization of SSTR1 and SSTR5 was also obtained in live cells using Fluorescence correlation spectroscopy techniques [92]. In these studies, although SSTR5 was demonstrated to form both homo- and heterodimers with SSTR1 in an agonist-regulated fashion, SSTR1 remained as a monomer when expressed alone despite its activation with agonist. Consistent with several other studies, dimerization is not always a necessary mechanism in GPCR activation $[119,120]$. Further, subsequent studies showed that SSTR5 and SSTR1 heterodimerization was specifically induced upon activation of SSTR5 and not via activation of SSTR1 [65]. In addition Grant et al. described the mechanism for SSTR heterodimerization and elucidate that C-tails of GPCRs are integral for G-protein coupling [65]. The mechanism for internalization and dimerization is confined to the C-tail of SSTR5 discovered by interchanging this segment to the SSTR1 [65]. SSTR5 exhibits homodimerization upon agonist activation which was diminished in the presence of SSTR1 C-tail. Conversely, SSTR1 with the
C-tail of SSTR5 displayed homodimerization in the presence of agonist, suggesting that $\mathrm{C}$-tail is critical in receptor dimerization [65]. Most importantly, the ability of SSTR4 to form homodimer was not observed with the C-tail of SSTR1 [106]. The specificity of the C-tail in the process of dimerization is not restricted to SSTR subtypes only but was also described for $\delta$-opioid receptor-trafficking and heterodimerization of GABABR subtypes GABABR1 and GABABR2 [34,37], and for $\mu$ and $\delta$-opioid receptor (ORs) heterodimerization [121].

SSTR1/SSTR5 heterodimerization leads to greater efficiency in signaling and inhibition of adenylate cyclase and cAMP synthesis [65]. Our recent studies revealed that cells co-expressing SSTR1/ SSTR5 showed a 50-fold increase in signaling efficiency with octreotide despite the lack of affinity for SSTR1 in comparison to cells expressing SSTR5 alone [65]. Increased signaling efficiency did not translate to increased efficacy suggesting that heterodimerization altered the message communicated. Reduced efficacy, suggests that SSTR1/SSTR5 heterodimers are less responsive to octreotide drug treatment and this has clinical implications in the treatment of human prolactinomas. These prolactin hypersecreting tumors found in the pituitary strongly co-express SSTR1 and SSTR5 subtypes [122,123]. Most importantly, tumors with strong SSTR1 expression levels respond more poorly to octreotide treatment than those with less SSTR1 expression regardless of SSTR5 presence [122].

\section{Physiological significance and clinical implication of somatostatin receptor heterodimerization}

Several previous studies provide evidence and support to the concept of that GPCRs represent the major target for new drugs development. Although, studies have described the pharmacological and physiological significance of SSTRs, however the role of SSTR subtypes in pathological conditions still remains elusive. SSTR subtypes not only interact as heterodimers with other closely related receptors including DR, AR and OR subtypes but also constitute functionally active complex with distantly related receptor protein such as NMDA receptors of ionotropic and epidermal growth factor receptors (EGFRs) of receptor tyrosine kinase (RTKs) families and govern many clinical implications [54,55,63,124-126]. If not all, most of the GPCR functions as homo-or heterodimers and the process of heterodimerization may enhance the existing functions of the native receptor. These unique properties of the receptor and therapies target the action of GPCR in pathological conditions have been used as one of the most favorable and successful therapeutic approach in designing the new drugs. The somatostatinergic system plays versatile role in different parts of the body to control hormonal secretion, regulation of ionic channels, modulation of signaling pathways and most importantly inhibition of cell proliferation in tumor with a significant promise for the development of new drugs in multiple therapeutic discipline with clinical outcome. In this direction significant progress has been made to understand the pathophysiology of pituitary tumor 'acromegaly' and somatostatin receptors [127]. Over $90 \%$ of patients on SST-analogs show reductions in circulating GH levels, while approximately $70 \%$ of those achieve biochemical normalization. Approximately $50 \%$ of patients will have tumor shrinkage with SST-analog treatment [128-133]. This property is specific to tumors of the pituitary whereas no other neuroendocrine tumors share this characteristic [130,134-137]. Incidentally, SSTR2 and SSTR5 are the two receptor subtypes predominantly expressed in GH hyper-secreting pituitary adenomas and therefore, heterodimerization of SSTR2/5 seen in presence of SST analogs could account for clinical outcomes [138,139]. Most importantly, future studies for the role of SSTR subtypes in neurodegenerative diseases will be of great importance. 
The possibility of functional crosstalk between SSTRs and ORs or/and adrenergic receptors may provide some pathophysiological significance in pain and heart failure respectively [124-126]. Recent studies from author laboratory describing that SSTRs functionally interact with EGFR and modulate tumors promoting signaling pathways are of great importance to understand the pathological significance of inverse relation of these two receptor proteins in tumor biology [54-56]. In the central nervous system colocalization of SSTR with NMDA receptors has been shown. Whether these receptors functionally interact with each other is not known and need to be determined in neuronal cells. If such interaction is established that will elucidate the new role of SSTR subtypes in regulation of ion gated channels and its implication in excitotoxicity and neurodegenerative diseases.

\section{Conclusions and future direction}

Dimerization of SSTR subtypes, with specific interest on heterodimerization within the family or other GPCRs, generates novel receptors with unique properties distinct from those of the individual monomers/homodimers and heterodimers complex of receptor. However, future studies are essential to ascertain the role of SSTR in regulating the receptor pharmacology, coupling to effectors molecules, physiological responses of cells and downstream signaling cascades. There are many questions still to answer and much remains to be explored in relation to SSTRs or in broader sense to GPCR homo-and/ or heterodimerization. In time to come, future studies with concept of clinical requirement in mind should be directed in pathological conditions. The regulations of cell surface receptor proteins hold the great promise in developing new drugs. Importantly, new studies on SSTRs heterodimerization with receptor tyrosine kinases will foster novel therapeutic approach in treatment of various tumors showing high expression of EGFR and resistance to tumor therapy. To study the clinical implication of SSTR homo-and heterodimerization future studies on receptor knockout and transgenic mice with disease phenotype will be useful approach to elucidate receptor specific role. In conclusion, to determine the cellular target of SSTRs heteromeric complexes in vivo and/or in pathological conditions will be worth of investigation in future.

\section{Acknowledgment}

The work cited in this review from author laboratory is referred to human somatostatin receptors and was supported by Canadian Institute of Health Research Grant (MOP 6196 and MOP 74465) and grant from Canadian Breast Cancer Foundation BC/Yukon to UK. UK is a Senior Scholar of Michael Smith Foundation for Health Research. Author is thankful to all former and present lab personals for their help in preparation of this article.

\section{References}

1. Kumar U, Grant M (2010) Somatostatin and somatostatin receptors. Results Probl Cell Differ 50: 137-184.

2. Patel YC (1999) Somatostatin and its receptor family. Front Neuroendocrinol 20: $157-198$

3. Bruns C, Weckbecker G, Raulf F, LÃ $1 / 4$ bbert H, Hoyer D (1995) Characterization of somatostatin receptor subtypes. Ciba Found Symp 190: 89-101.

4. Csaba Z, Dournaud P (2001) Cellular biology of somatostatin receptors. Neuropeptides 35: 1-23.

5. Hipkin RW, Friedman J, Clark RB, Eppler CM, Schonbrunn A (1997) Agonistinduced desensitization, internalization, and phosphorylation of the sst2A somatostatin receptor. J Biol Chem 272: 13869-13876.

6. Hukovic N, Panetta R, Kumar U, Patel YC (1996) Agonist-dependent regulation of cloned human somatostatin receptor types 1-5 (hSSTR1-5): subtype selective internalization or upregulation. Endocrinology 137: 4046-4049.
7. Hukovic N, Panetta R, Kumar U, Rocheville M, Patel YC (1998) The cytoplasmic tail of the human somatostatin receptor type 5 is crucial for interaction with adenylyl cyclase and in mediating desensitization and internalization. J Biol Chem 273: 21416-21422.

8. Hukovic N, Rocheville M, Kumar U, Sasi R, Khare S, et al. (1999) Agonistdependent up-regulation of human somatostatin receptor type 1 requires molecular signals in the cytoplasmic C-tail. J Biol Chem 274: 24550-24558.

9. Kreienkamp HJ, Roth A, Richter D (1998) Rat somatostatin receptor subtype 4 can be made sensitive to agonist-induced internalization by mutation of a single threonine (residue 331). DNA Cell Biol 17: 869-878.

10. Liu Q, Schonbrunn A (2001) Agonist-induced phosphorylation of somatostatin receptor subtype 1 (sst1). Relationship to desensitization and internalization. J Biol Chem 276: 3709-3717.

11. RamÃrez JL, Mouchantaf R, Kumar U, Otero Corchon V, Rubinstein M, et al (2002) Brain somatostatin receptors are up-regulated in somatostatin-deficient mice. Mol Endocrinol 16: 1951-1963.

12. Roth A, Kreienkamp HJ, Meyerhof W, Richter D (1997) Phosphorylation of four amino acid residues in the carboxyl terminus of the rat somatostatin receptor subtype 3 is crucial for its desensitization and internalization. J Biol Chem 272: 23769-23774.

13. Schreff M, Schulz S, HÃandel M, Keilhoff G, Braun H, et al. (2000) Distribution, targeting, and internalization of the sst4 somatostatin receptor in rat brain. $J$ Neurosci 20: 3785-3797.

14. Bouvier M (2001) Oligomerization of G-protein-coupled transmitter receptors. Nat Rev Neurosci 2: 274-286.

15. Breitwieser GE (2004) G protein-coupled receptor oligomerization: implications for $\mathrm{G}$ protein activation and cell signaling. Circ Res 94: 17-27.

16. George SR, O'Dowd BF, Lee SP (2002) G-protein-coupled receptor oligomerization and its potential for drug discovery. Nat Rev Drug Discov 1: 808-820.

17. Milligan G (2009) G protein-coupled receptor hetero-dimerization: contribution to pharmacology and function. $\mathrm{Br} \mathrm{J}$ Pharmacol 158: 5-14.

18. Gregory H, Taylor CL, Hopkins CR (1982) Luteinizing hormone release from dissociated pituitary cells by dimerization of occupied LHRH receptors. Nature 300: 269-271.

19. Fraser CM, Venter JC (1982) The size of the mammalian lung beta 2-adrenergic receptor as determined by target size analysis and immunoaffinity chromatography. Biochem Biophys Res Commun 109: 21-29.

20. Paglin S, Jamieson JD (1982) Covalent crosslinking of angiotensin II to its binding sites in rat adrenal membranes. Proc Natl Acad Sci U S A 79: 37393743.

21. HÃ@bert TE, Bouvier M (1998) Structural and functional aspects of G proteincoupled receptor oligomerization. Biochem Cell Biol 76: 1-11.

22. Bulenger S, Marullo S, Bouvier M (2005) Emerging role of homo- and heterodimerization in G-protein-coupled receptor biosynthesis and maturation. Trends Pharmacol Sci 26: 131-137.

23. Maggio R, Vogel Z, Wess J (1993) Coexpression studies with mutant muscarinic/ adrenergic receptors provide evidence for intermolecular "cross-talk" between G-protein-linked receptors. Proc Natl Acad Sci U S A 90: 3103-3107.

24. Monnot C, Bihoreau C, Conchon S, Curnow KM, Corvol P, et al. (1996) Polar residues in the transmembrane domains of the type 1 angiotensin II receptor are required for binding and coupling. Reconstitution of the binding site by coexpression of two deficient mutants. J Biol Chem 271: 1507-1513.

25. Osuga Y, Hayashi M, Kudo M, Conti M, Kobilka B, et al. (1997) Co-expression of defective luteinizing hormone receptor fragments partially reconstitutes ligand-induced signal generation. J Biol Chem 272: 25006-25012.

26. Schöneberg T, Sandig V, Wess J, Gudermann T, Schultz G (1997) Reconstitution of mutant V2 vasopressin receptors by adenovirus-mediated gene transfer. Molecular basis and clinical implication. J Clin Invest 100: 1547-1556.

27. Schoneberg T, Yun J, Wenkert D, Wess J (1996) Functional rescue of mutant V2 vasopressin receptors causing nephrogenic diabetes insipidus by a coexpressed receptor polypeptide. EMBO J 15: 1283-1291.

28. Schulz A, Grosse R, Schultz G, Gudermann T, Schöneberg T (2000) Structural implication for receptor oligomerization from functional reconstitution studies of mutant V2 vasopressin receptors. J Biol Chem 275: 2381-2389. 
29. Hebert TE, Moffett S, Morello JP, Loisel TP, Bichet DG, et al. (1996) A peptide derived from a beta2-adrenergic receptor transmembrane domain inhibits both receptor dimerization and activation. J Biol Chem 271: 16384-16392.

30. Cvejic S, Devi LA (1997) Dimerization of the delta opioid receptor: implication for a role in receptor internalization. J Biol Chem 272: 26959-26964.

31. Kaupmann K, Huggel K, Heid J, Flor PJ, Bischoff S, et al. (1997) Expression cloning of $G A B A(B)$ receptors uncovers similarity to metabotropic glutamate receptors. Nature 386: 239-246.

32. Kaupmann K, Malitschek B, Schuler V, Heid J, Froestl W, et al. (1998) $\mathrm{GABA}(\mathrm{B})$-receptor subtypes assemble into functional heteromeric complexes. Nature 396: 683-687.

33. Jones KA, Borowsky B, Tamm JA, Craig DA, Durkin MM, et al. (1998) GABA(B) receptors function as a heteromeric assembly of the subunits $G A B A(B) R 1$ and GABA(B)R2. Nature 396: 674-679.

34. Kuner R, Köhr G, Grünewald S, Eisenhardt G, Bach A, et al. (1999) Role of heteromer formation in GABAB receptor function. Science 283: 74-77.

35. Martin SC, Russek SJ, Farb DH (1999) Molecular identification of the human GABABR2: cell surface expression and coupling to adenylyl cyclase in the absence of GABABR1. Mol Cell Neurosci 13: 180-191.

36. Ng GY, Clark J, Coulombe N, Ethier N, Hebert TE, et al. (1999) Identification of a GABAB receptor subunit, gb2, required for functional $G A B A B$ receptor activity. J Biol Chem 274: 7607-7610.

37. White JH, Wise A, Main MJ, Green A, Fraser NJ, et al. (1998) Heterodimerization is required for the formation of a functional GABA(B) receptor. Nature 396: 679682.

38. Pagano A, Rovelli G, Mosbacher J, Lohmann T, Duthey B, et al. (2001) C-terminal interaction is essential for surface trafficking but not for heteromeric assembly of GABA(b) receptors. J Neurosci 21: 1189-1202.

39. Calver AR, Robbins MJ, Cosio C, Rice SQ, Babbs AJ, et al. (2001) The C-terminal domains of the $\mathrm{GABA}(\mathrm{b})$ receptor subunits mediate intracellular trafficking but are not required for receptor signaling. J Neurosci 21: 1203-1210.

40. Cole TJ, Harris HJ, Hoong I, Solomon N, Smith R, et al. (1999) The glucocorticoid receptor is essential for maintaining basal and dexamethasoneinduced repression of the murine corticosteroid-binding globulin gene. Mol Cell Endocrinol 154: 29-36.

41. Bachmanov AA, Li X, Reed DR, Ohmen JD, Li S, et al. (2001) Positional cloning of the mouse saccharin preference (Sac) locus. Chem Senses 26: 925-933.

42. Kitagawa M, Kusakabe Y, Miura H, Ninomiya Y, Hino A (2001) Molecular genetic identification of a candidate receptor gene for sweet taste. Biochem Biophys Res Commun 283: 236-242.

43. Max M, Shanker YG, Huang L, Rong M, Liu Z, et al. (2001) Tas1r3, encoding a new candidate taste receptor, is allelic to the sweet responsiveness locus Sac. Nat Genet 28: 58-63.

44. Montmayeur JP, Liberles SD, Matsunami H, Buck LB (2001) A candidate taste receptor gene near a sweet taste locus. Nat Neurosci 4: 492-498.

45. Nelson G, Hoon MA, Chandrashekar J, Zhang Y, Ryba NJ, et al. (2001) Mammalian sweet taste receptors. Cell 106: 381-390.

46. Sainz E, Korley JN, Battey JF, Sullivan SL (2001) Identification of a novel member of the T1R family of putative taste receptors. J Neurochem 77: 896903.

47. Bai M, Trivedi S, Kifor O, Quinn SJ, Brown EM (1999) Intermolecular interactions between dimeric calcium-sensing receptor monomers are important for its normal function. Proc Natl Acad Sci U S A 96: 2834-2839.

48. Jensen AA, Hansen JL, Sheikh SP, BrÃauner-Osborne H (2002) Probing intermolecular protein-protein interactions in the calcium-sensing receptor homodimer using bioluminescence resonance energy transfer (BRET). Eur $\mathrm{J}$ Biochem 269: 5076-5087

49. Pin JP, Kniazeff J, Liu J, Binet V, Goudet C, et al. (2005) Allosteric functioning of dimeric class C G-protein-coupled receptors. FEBS J 272: 2947-2955.

50. Bai M, Trivedi S, Brown EM (1998) Dimerization of the extracellular calciumsensing receptor $(\mathrm{CaR})$ on the cell surface of CaR-transfected HEK293 cells. J Biol Chem 273: 23605-23610

51. Kunishima N, Shimada Y, Tsuji Y, Sato T, Yamamoto M, et al. (2000) Structural basis of glutamate recognition by a dimeric metabotropic glutamate receptor. Nature 407: 971-977.
52. Lee FJ, Xue S, Pei L, Vukusic B, ChÃ@ry N, et al. (2002) Dual regulation of NMDA receptor functions by direct protein-protein interactions with the dopamine D1 receptor. Cell 111: 219-230.

53. Pei L, Li S, Wang M, Diwan M, Anisman H, et al. (2010) Uncoupling the dopamine D1-D2 receptor complex exerts antidepressant-like effects. Nat Med 16: $1393-1395$.

54. Kharmate G, Rajput PS, Watt HL, Somvanshi RK, Chaudhari N, et al. (2011) Dissociation of epidermal growth factor receptor and ErbB2 heterodimers in the presence of somatostatin receptor 5 modulate signaling pathways. Endocrinology 152: 931-945

55. Watt HL, Kharmate GD, Kumar U (2009) Somatostatin receptors 1 and 5 heterodimerize with epidermal growth factor receptor: agonist-dependent modulation of the downstream MAPK signalling pathway in breast cancer cells Cell Signal 21: 428-439.

56. Watt HL, Kharmate G, Kumar U (2008) Biology of somatostatin in breast cancer. Mol Cell Endocrinol 286: 251-261.

57. Angers S, Salahpour A, Joly E, Hilairet S, Chelsky D, et al. (2000) Detection of beta 2-adrenergic receptor dimerization in living cells using bioluminescence resonance energy transfer (BRET). Proc Natl Acad Sci U S A 97: 3684-3689.

58. Overton MC, Blumer KJ (2000) G-protein-coupled receptors function as oligomers in vivo. Curr Biol 10: 341-344.

59. Rocheville M, Lange DC, Kumar U, Sasi R, Patel RC, et al. (2000) Subtypes of the somatostatin receptor assemble as functional homo- and heterodimers. J Biol Chem 275: 7862-7869.

60. Gadella TW Jr, Jovin TM (1995) Oligomerization of epidermal growth factor receptors on A431 cells studied by time-resolved fluorescence imaging microscopy. A stereochemical model for tyrosine kinase receptor activation. $J$ Cell Biol 129: 1543-1558.

61. Kubitscheck U, Kircheis M, Schweitzer-Stenner R, Dreybrodt W, Jovin TM et al. (1991) Fluorescence resonance energy transfer on single living cells. Application to binding of monovalent haptens to cell-bound immunoglobulin $\mathrm{E}$. Biophys J 60: 307-318.

62. Young RM, Arnette JK, Roess DA, Barisas BG (1994) Quantitation of fluorescence energy transfer between cell surface proteins via fluorescence donor photobleaching kinetics. Biophys J 67: 881-888.

63. Rocheville M, Lange DC, Kumar U, Patel SC, Patel RC, et al. (2000) Receptors for dopamine and somatostatin: formation of hetero-oligomers with enhanced functional activity. Science 288: 154-157.

64. Grant M, Collier B, Kumar U (2004) Agonist-dependent dissociation of human somatostatin receptor 2 dimers: a role in receptor trafficking. J Biol Chem 279 36179-36183.

65. Grant M, Patel RC, Kumar U (2004) The role of subtype-specific ligand binding and the $\mathrm{C}$-tail domain in dimer formation of human somatostatin receptors. $J$ Biol Chem 279: 38636-38643.

66. Dinger MC, Bader JE, Kobor AD, Kretzschmar AK, Beck-Sickinger AG (2003) Homodimerization of neuropeptide $y$ receptors investigated by fluorescence resonance energy transfer in living cells. J Biol Chem 278: 10562-10571.

67. Springael JY, Urizar E, Costagliola S, Vassart G, Parmentier M (2007) Allosteric properties of $\mathrm{G}$ protein-coupled receptor oligomers. Pharmacol Ther 115: 410418.

68. Briddon SJ, Hill SJ (2007) Pharmacology under the microscope: the use of fluorescence correlation spectroscopy to determine the properties of ligandreceptor complexes. Trends Pharmacol Sci 28: 637-645.

69. Smith TH, Sim-Selley LJ, Selley DE (2010) Cannabinoid CB1 receptorinteracting proteins: novel targets for central nervous system drug discovery? Br J Pharmacol 160: 454-466.

70. Sansuk K, Balog Cl, van der Does AM, Booth R, de Grip WJ, et al. (2008) GPCR proteomics: mass spectrometric and functional analysis of histamine $\mathrm{H} 1$ receptor after baculovirus-driven and in vitro cell free expression. J Proteome Res 7: 621-629.

71. Hermans $E$ (2003) Biochemical and pharmacological control of the multiplicity of coupling at G-protein-coupled receptors. Pharmacol Ther 99: 25-44.

72. Liu AM, Wong YH (2005) Activation of nuclear factor \{kappa\}B by somatostatin type 2 receptor in pancreatic acinar AR42J cells involves G\{alpha\}14 and multiple signaling components: a mechanism requiring protein kinase $\mathrm{C}$ calmodulin-dependent kinase II, ERK, and c-Src. J Biol Chem 280: 3461734625. 
73. Pitcher JA, Hall RA, Daaka Y, Zhang J, Ferguson SS, et al. (1998) The G protein-coupled receptor kinase 2 is a microtubule-associated protein kinase that phosphorylates tubulin. J Biol Chem 273: 12316-12324.

74. Daaka Y, Luttrell LM, Ahn S, Della Rocca GJ, Ferguson SS, et al. (1998) Essential role for $\mathrm{G}$ protein-coupled receptor endocytosis in the activation of mitogen-activated protein kinase. J Biol Chem 273: 685-688.

75. Lefkowitz RJ (1998) G protein-coupled receptors. III. New roles for receptor kinases and beta-arrestins in receptor signaling and desensitization. $\mathrm{J}$ Biol Chem 273: 18677-18680.

76. Krupnick JG, Benovic JL (1998) The role of receptor kinases and arrestins in G protein-coupled receptor regulation. Annu Rev Pharmacol Toxicol 38: 289-319.

77. Krupnick JG, Santini F, Gagnon AW, Keen JH, Benovic JL (1997) Modulation of the arrestin-clathrin interaction in cells. Characterization of beta-arrestin dominant-negative mutants. J Biol Chem 272: 32507-32512.

78. Goodman OB Jr, Krupnick JG, Santini F, Gurevich VV, Penn RB, et al. (1998) Role of arrestins in G-protein-coupled receptor endocytosis. Adv Pharmacol 42: 429-433.

79. Grant M, Alturaihi H, Jaquet P, Collier B, Kumar U (2008) Cell growth inhibition and functioning of human somatostatin receptor type 2 are modulated by receptor heterodimerization. Mol Endocrinol 22: 2278-2292.

80. Hay DL, Poyner DR, Sexton PM (2006) GPCR modulation by RAMPs. Pharmacol Ther 109: 173-197.

81. Brady AE, Limbird LE (2002) G protein-coupled receptor interacting proteins: emerging roles in localization and signal transduction. Cell Signal 14: 297-309.

82. Magalhaes AC, Dunn H, Ferguson SS (2012) Regulation of GPCR activity trafficking and localization by GPCR-interacting proteins. Br J Pharmacol 165: 1717-1736.

83. Bouschet T, Martin S, Henley JM (2005) Receptor-activity-modifying proteins are required for forward trafficking of the calcium-sensing receptor to the plasma membrane. J Cell Sci 118: 4709-4720.

84. Bouschet T, Henley JM (2005) Calcium as an extracellular signalling molecule: perspectives on the Calcium Sensing Receptor in the brain. C R Biol 328: 691700 .

85. Schwencke C, Okumura S, Yamamoto M, Geng YJ, Ishikawa Y (1999) Colocalization of beta-adrenergic receptors and caveolin within the plasma membrane. J Cell Biochem 75: 64-72.

86. Xiang Y, Rybin VO, Steinberg SF, Kobilka B (2002) Caveolar localization dictates physiologic signaling of beta 2-adrenoceptors in neonatal cardiac myocytes. J Biol Chem 277: 34280-34286.

87. Ostrom RS, Post SR, Insel PA (2000) Stoichiometry and compartmentation in $G$ protein-coupled receptor signaling: implications for therapeutic interventions involving G(s). J Pharmacol Exp Ther 294: 407-412.

88. Ostrom RS, Violin JD, Coleman S, Insel PA (2000) Selective enhancement of beta-adrenergic receptor signaling by overexpression of adenylyl cyclase type 6: colocalization of receptor and adenylyl cyclase in caveolae of cardiac myocytes. Mol Pharmacol 57: 1075-1079.

89. Ostrom RS, Gregorian C, Drenan RM, Xiang Y, Regan JW, et al. (2001) Receptor number and caveolar co-localization determine receptor coupling efficiency to adenylyl cyclase. J Biol Chem 276: 42063-42069.

90. Rybin VO, Xu X, Lisanti MP, Steinberg SF (2000) Differential targeting of beta -adrenergic receptor subtypes and adenylyl cyclase to cardiomyocyte caveolae. A mechanism to functionally regulate the cAMP signaling pathway. $\mathrm{J}$ Biol Chem 275: 41447-41457.

91. DurÃ $i n-P r a d o ~ M, ~ M a l a g \tilde{A}^{3} n$ MM, Gracia-Navarro F, CastaÃ to JP (2008) Dimerization of $G$ protein-coupled receptors: new avenues for somatostatin receptor signalling, control and functioning. Mol Cell Endocrinol 286: 63-68.

92. Patel RC, Kumar U, Lamb DC, Eid JS, Rocheville M, et al. (2002) Ligand binding to somatostatin receptors induces receptor-specific oligomer formation in live cells. Proc Natl Acad Sci U S A 99: 3294-3299.

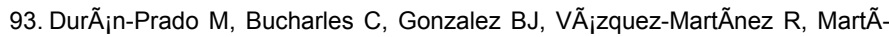
nez-Fuentes AJ, et al. (2007) Porcine somatostatin receptor 2 displays typical pharmacological sst2 features but unique dynamics of homodimerization and internalization. Endocrinology 148: 411-421.

94. Berglund MM, Schober DA, Esterman MA, Gehlert DR (2003) Neuropeptide Y Y4 receptor homodimers dissociate upon agonist stimulation. J Pharmacol Exp Ther 307: 1120-1126.
95. Cheng ZJ, Miller LJ (2001) Agonist-dependent dissociation of oligomeric complexes of $G$ protein-coupled cholecystokinin receptors demonstrated in living cells using bioluminescence resonance energy transfer. J Biol Chem 276 48040-48047.

96. GinÃ@s S, Hillion J, Torvinen M, Le Crom S, Casad $\tilde{A}^{3}$ V, et al. (2000) Dopamine $\mathrm{D} 1$ and adenosine $\mathrm{A} 1$ receptors form functionally interacting heteromeric complexes. Proc Natl Acad Sci U S A 97: 8606-8611.

97. Latif R, Graves P, Davies TF (2002) Ligand-dependent inhibition of oligomerization at the human thyrotropin receptor. J Biol Chem 277: 4505945067.

98. Law PY, Erickson-Herbrandson LJ, Zha QQ, Solberg J, Chu J, et al. (2005) Heterodimerization of mu- and delta-opioid receptors occurs at the cell surface only and requires receptor-G protein interactions. J Biol Chem 280: 1115211164

99. Pfeiffer M, Koch T, Schroder H, Klutzny M, Kirscht S, et al. (2001) Homo- and heterodimerization of somatostatin receptor subtypes. Inactivation of sst(3) receptor function by heterodimerization with sst(2A). J Biol Chem 276: 1402714036.

100. Perron A, Chen ZG, Gingras D, Dupre DJ, Stankova J, et al. (2003) Agonistindependent desensitization and internalization of the human plateletactivating factor receptor by coumermycin-gyrase B-induced dimerization. $J$ Biol Chem 278: 27956-27965.

101. Song GJ, Hinkle PM (2005) Regulated dimerization of the thyrotropin-releasing hormone receptor affects receptor trafficking but not signaling. Mol Endocrinol 19: $2859-2870$

102. War SA, Somvanshi RK, Kumar U (2011) Somatostatin receptor-3 mediated intracellular signaling and apoptosis is regulated by its cytoplasmic terminal. Biochim Biophys Acta 1813: 390-402.

103. War SA, Kumar U (2012) Coexpression of human somatostatin receptor-2 (SSTR2) and SSTR3 modulates antiproliferative signaling and apoptosis. J Mol Signal 7: 5 .

104. Van Op den Bosch J, Torfs P, De Winter BY, De Man JG, Pelckmans PA, et al (2009) Effect of genetic SSTR4 ablation on inflammatory peptide and receptor expression in the non-inflamed and inflamed murine intestine. J Cell Mol Med 13: 3283-3295

105. Van Op den Bosch J, van Nassauw L, Lantermann K, van Marck E, Timmermans JP (2007) Effect of intestinal inflammation on the cell-specific expression of somatostatin receptor subtypes in the murine ileum. Neurogastroenterol Motil 19: $596-606$

106. Somvanshi RK, Billova S, Kharmate G, Rajput PS, Kumar U (2009) C-tail mediated modulation of somatostatin receptor type-4 homo- and heterodimerizations and signaling. Cell Signal 21: 1396-1414.

107. Cervera P, Videau C, Viollet C, Petrucci C, Lacombe J, et al. (2002) Comparison of somatostatin receptor expression in human gliomas and medulloblastomas. J Neuroendocrinol 14: 458-471.

108. Viollet C, Bodenant C, Prunotto C, Roosterman D, Schaefer J, et al. (1997) Differential expression of multiple somatostatin receptors in the rat cerebellum during development. J Neurochem 68: 2263-2272.

109. Grant M, Kumar U (2010) The role of G-proteins in the dimerisation of human somatostatin receptor types 2 and 5. Regul Pept 159: 3-8.

110. Baragli A, Alturaihi H, Watt HL, Abdallah A, Kumar U (2007) Heterooligomerization of human dopamine receptor 2 and somatostatin receptor 2 Co-immunoprecipitation and fluorescence resonance energy transfer analysis. Cell Signal 19: 2304-2316.

111. McGraw DW, Mihlbachler KA, Schwarb MR, Rahman FF, Small KM, et al (2006) Airway smooth muscle prostaglandin-EP1 receptors directly modulate beta2-adrenergic receptors within a unique heterodimeric complex. J Clin Invest 116: 1400-1409.

112. Jiang H, Betancourt L, Smith RG (2006) Ghrelin amplifies dopamine signaling by cross talk involving formation of growth hormone secretagogue receptor/ dopamine receptor subtype 1 heterodimers. Mol Endocrinol 20: 1772-1785.

113. Kearn CS, Blake-Palmer K, Daniel E, Mackie K, Glass M (2005) Concurrent stimulation of cannabinoid CB1 and dopamine D2 receptors enhances heterodimer formation: a mechanism for receptor cross-talk? Mol Pharmacol 67: 1697-1704. 
Citation: Kumar U (2013) G-Protein Coupled Receptors Dimerization: Diversity in Somatostatin Receptors Subtypes. J Pharmacogenom Pharmacoproteomics 4: 120. doi:10.4172/2153-0645.1000120

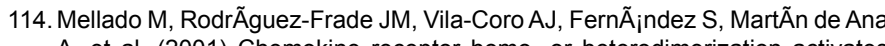
A, et al. (2001) Chemokine receptor homo- or heterodimerization activates distinct signaling pathways. EMBO J 20: 2497-2507.

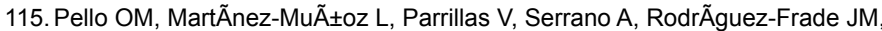
et al. (2008) Ligand stabilization of CXCR4/delta-opioid receptor heterodimers reveals a mechanism for immune response regulation. Eur J Immunol 38: 537 549.

116. RodrÃguez-Frade JM, del Real G, Serrano A, Hernanz-FalcÃ ${ }^{3} n$ P, Soriano SF, et al. (2004) Blocking HIV-1 infection via CCR5 and CXCR4 receptors by acting in trans on the CCR2 chemokine receptor. EMBO J 23: 66-76.

117. Yoshioka K, Saitoh O, Nakata H (2002) Agonist-promoted heteromeric oligomerization between adenosine $\mathrm{A}(1)$ and $\mathrm{P} 2 \mathrm{Y}(1)$ receptors in living cells. FEBS Lett 523: 147-151.

118. Patel YC, Greenwood MT, Warszynska A, Panetta R, Srikant CB (1994) All five cloned human somatostatin receptors (hSSTR1-5) are functionally coupled to adenylyl cyclase. Biochem Biophys Res Commun 198: 605-612.

119. Gripentrog JM, Kantele KP, Jesaitis AJ, Miettinen HM (2003) Experimental evidence for lack of homodimerization of the $G$ protein-coupled human N-formyl peptide receptor. J Immunol 171: 3187-3193.

120. Meyer BH, Segura JM, Martinez KL, Hovius R, George N, et al. (2006) FRET imaging reveals that functional neurokinin-1 receptors are monomeric and reside in membrane microdomains of live cells. Proc Natl Acad Sci U S A 103 2138-2143.

121. Fan T, Varghese G, Nguyen T, Tse R, O'Dowd BF, et al. (2005) A role for the distal carboxyl tails in generating the novel pharmacology and $\mathrm{G}$ protein activation profile of $\mathrm{mu}$ and delta opioid receptor hetero-oligomers. J Biol Chem 280: 38478-38488.

122. Jaquet P, Ouafik L, Saveanu A, Gunz G, Fina F, et al. (1999) Quantitative and functional expression of somatostatin receptor subtypes in human prolactinomas. J Clin Endocrinol Metab 84: 3268-3276.

123. Shimon I, Yan X, Taylor JE, Weiss MH, Culler MD, et al. (1997) Somatostatin receptor (SSTR) subtype-selective analogues differentially suppress in vitro growth hormone and prolactin in human pituitary adenomas. Novel potential therapy for functional pituitary tumors. J Clin Invest 100: 2386-2392.

124.Pfeiffer M, Koch T, Schröder H, Laugsch M, Höllt V, et al. (2002) Heterodimerization of somatostatin and opioid receptors cross-modulates phosphorylation, internalization, and desensitization. J Biol Chem 277: $19762-$ 19772.

125. Somvanshi RK, Chaudhari N, Qiu X, Kumar U (2011) Heterodimerization of î22 adrenergic receptor and somatostatin receptor 5: Implications in modulation of signaling pathway. J Mol Signal 6: 9 .
126. Somvanshi RK, War SA, Chaudhari N, Qiu X, Kumar U (2011) Receptor specific crosstalk and modulation of signaling upon heterodimerization between $\hat{i}^{2} 1$-adrenergic receptor and somatostatin receptor-5. Cell Signal 23 794-811.

127. Tichomirowa MA, Daly AF, Beckers A (2005) Treatment of pituitary tumors: somatostatin. Endocrine 28: 93-100.

128.Bevan JS (2005) Clinical review: The antitumoral effects of somatostatin analog therapy in acromegaly. J Clin Endocrinol Metab 90: 1856-1863.

129. Ferrante E, Pellegrini C, Bondioni S, Peverelli E, Locatelli M, et al. (2006) Octreotide promotes apoptosis in human somatotroph tumor cells by activating somatostatin receptor type 2. Endocr Relat Cancer 13: 955-962.

130.130. Lamberts SW, de Herder WW, Hofland LJ (2002) Somatostatin analogs in the diagnosis and treatment of cancer. Trends Endocrinol Metab 13: 451-457.

131. Melmed S, Sternberg R, Cook D, Klibanski A, Chanson P, et al. (2005) A critical analysis of pituitary tumor shrinkage during primary medical therapy in acromegaly. J Clin Endocrinol Metab 90: 4405-4410.

132. Resmini E, Dadati P, Ravetti JL, Zona G, Spaziante R, et al. (2007) Rapid pituitary tumor shrinkage with dissociation between antiproliferative and antisecretory effects of a long-acting octreotide in an acromegalic patient. $J$ Clin Endocrinol Metab 92: 1592-1599.

133.Zatelli MC, Piccin D, Ambrosio MR, Bondanelli M, degli Uberti EC (2006) Antiproliferative effects of somatostatin analogs in pituitary adenomas. Pituitary 9: 27-34

134. de Herder WW, Hofland LJ, van der Lely AJ, Lamberts SW (2003) Somatostatin receptors in gastroentero-pancreatic neuroendocrine tumours. Endocr Relat Cancer 10: 451-458

135. Hofland LJ, Lamberts SW (2003) The pathophysiological consequences of somatostatin receptor internalization and resistance. Endocr Rev 24: 28-47.

136. Lamberts SW, Krenning EP, Reubi JC (1991) The role of somatostatin and its analogs in the diagnosis and treatment of tumors. Endocr Rev 12: 450-482.

137. Lamberts SW, van der Lely AJ, de Herder WW, Hofland LJ (1996) Somatostatin analogs: future directions. Metabolism 45: 104-106

138. Jaquet P, Saveanu A, Gunz G, Fina F, Zamora AJ, et al. (2000) Human somatostatin receptor subtypes in acromegaly: distinct patterns of messenge ribonucleic acid expression and hormone suppression identify different tumoral phenotypes. J Clin Endocrinol Metab 85: 781-792.

139. Park C, Yang I, Woo J, Kim S, Kim J, et al. (2004) Somatostatin (SRIF) receptor subtype 2 and 5 gene expression in growth hormone-secreting pituitary adenomas: the relationship with endogenous srif activity and response to octreotide. Endocr J 51: 227-236. 